\title{
Pernicious anaemia and endocrine glands antibodies
}

\author{
Elżbieta Morawiec-Szymonik², Wanda Foltyn' ${ }^{1}$, Bogdan Marek', Beata Kos-Kudła' ${ }^{1}$, Dariusz Kajdaniuk ${ }^{1}$ \\ ${ }^{1}$ Department of Pathophysiology and Endocrinology, School of Medicine with the Division of Dentistry in Zabrze, \\ Medical University of Silesia, Katowice, Poland \\ ${ }^{2}$ Ward of Haematology, City Hospital, Chorzów, Poland
}

\begin{abstract}
Introduction: The aim of the study was to determine the frequency of occurrence of antibodies participating in the development of endocrine diseases in patients with autoimmune haematopoietic disease, thus documenting the potential suitability of specific diagnostic and screening tests.

Material and methods: The study group consisted of 124 persons (men and women) with newly diagnosed pernicious anaemia (PA) and a control group (C) of 41 healthy people. Antibodies against: intrinsic factor (IFAb), gastric parietal cells (APCA), thyroid peroxidase $(\mathrm{TPOAb})$, thyroglobulin $(\mathrm{TgAb})$, adrenal cortex (Adrenal $\mathrm{Ab}$ ), and pituitary anterior lobe (PituitaryAb) were determined in the blood. Results: 1 . The risk of the presence of antibodies against endocrine glands in patients with PA can be classified in order: TPOAb and/or $\mathrm{TgAb}-41.1 \%, \mathrm{TPOAb}-36.3 \%$, TgAb - 25.0\%, TPOAb and TgAb - 20.2\%, AdrenalAb - 1.6\%, PituitaryAb - 0.8\%. 2. TPOAb and/or $\mathrm{TgAb}$ (mainly TPOAb) are more frequently present in patients with PA, who have IFAb and/or APCA. This correlation is most evident in patients with simultaneous occurrence of IFAb and APCA. 3. Among patients with PA, the simultaneous presence of antibodies IFAb and/ or APCA with TPOAb and/or TgAb antibodies is most likely in women over 45 years of age. 4 . In group C, $12 \%$ had at least one of two antithyroid antibodies (TgAb twice as often as TPOAb), and $2.4 \%$ had both. AdrenalAb and PituitaryAb are not found in healthy persons. Conclusions: In patients with PA, a screening for autoimmune thyroid disease is justified, which should first involve the determination of TPOAb (further TgAb) in the blood. The assessment of antithyroid antibodies should be recommended primarily to patients with PA, who have IFAb and/or APCA, and in particular those with concurrent IFAb and APCA. (Endokrynol Pol 2019; 70 (2): 143-150)
\end{abstract}

Key words: pernicious anaemia; antibody; thyroid; adrenal; pituitary; Hashimoto; autoimmune disease

\section{Introduction}

Pernicious anaemia (PA; Biermer's disease, Addisonian anaemia) is characterised by chronic atrophic gastritis, impaired production of intrinsic factor (IF; Castle Factor) by gastric parietal cells and reduced resorption of vitamin $B_{12}$ from the ileum. IF has transport and protective functions for vitamin $B_{12}$. In the clinical picture of the disease there are a number of dysfunctions in the digestive system (histamine-resistant achlorhydria, decreased appetite and body weight, burning and tongue pain) and nervous system (muscle weakness, atrophy, hearing loss, irritability, depressive disorders, impairment of cognitive functions). An increased risk of developing stomach cancer in people with PA was observed. The haematological clinical symptom is megaloblastic anaemia with typical fatigability and effort dyspnoea. Pernicious anaemia is an autoimmune disease - anti-intrinsic factor antibodies (IFAb) (specific) and anti-parietal cell antibodies (APCA) (low specificity) are involved in its pathogenesis [1-16].
In patients with diagnosed autoimmune disease, changes in the functioning of other organs/systems often develop with time (or simultaneously). Probably it is the result of general immune disturbances accompanying these diseases as well as cross reactions that show many types of antibodies [13, 16-25]. Understanding the pathomechanism of the above phenomenon and expanding the diagnosis to detect the dysfunction of the other organ even before a clear clinical manifestation of the primary disease is justified, especially because starting the primary disease treatment can make this diagnosis more difficult. In this context, the coexistence of pathologies of the haematopoietic system with an immunological basis with other diseases of similar aetiology confirms the legitimacy of the implementation of a wider panel of examinations at the onset of the initial symptoms of one of the diseases mentioned above.

The aim of the study was to determine the frequency of occurrence of antibodies participating in the development of endocrine diseases in patients with 
autoimmune haematopoietic disease (PA), thus documenting the potential suitability of specific diagnostic and screening tests.

\section{Characteristics of the antibodies tested}

IFAb are specific for PA but are not detected in all patients. The diagnostic sensitivity of APCA for PA is very high; however, the specificity is limited due to the numerous other diseases in which these antibodies are present. APCA are detected in almost every case of PA, but often also in the course of gastritis without anaemia. APCA does not occur in healthy people $[3,4,8,9,13$, 14, 16, 20, 26-29].

High titres of anti-thyroid peroxidase antibodies (TPOAb) and/or anti-thyroglobulin antibodies (TgAb) are typical for autoimmune thyroid disease (AITD) - Hashimoto disease (atrophic or with goitre), and Graves' disease. Their concentration in the blood often correlates with the clinical condition. These antibodies are responsible for the destruction of thyrocytes. They can occur in a low percentage of healthy people, and their occurrence in the population increases with age. TPOAb and TgAb were found in people without clinical biochemical and ultrasonographic symptoms of diseases of the thyroid gland are a predictor of their development, in particular of hypothyroidism.

Anti-adrenal antibodies (AdrenalAb) are detected in some patients with Addison's disease, often after many years, and their concentration does not correlate with the course of the disease. These antibodies are primarily directed against steroid 21-hydroxylase. Addison's disease in $60-80 \%$ of cases has an autoimmune basis, which is associated with the destruction of the adrenal cortex and leads to its failure in the secretion of glyco- and mineralocorticoids. These antibodies are rarely determined by clinicians, and only their clinical utility is evaluated [25].

Anti-pituitary antibodies (PituitaryAb) probably arise not only in patients with autoimmune pituitary inflammation, but also as a result of necrosis, damage, or inflammation such as lymphocytic pituitary inflammation. Their participation in the pathomechanism of pituitary insufficiency has not yet been determined. These antibodies are extremely rarely determined by clinicians, and their clinical utility is also being evaluated [30-33].

\section{Material and methods}

\section{Patients}

The research project was approved by the Bioethical Commission of the Medical University of Silesia (Resolution No. KNW/0022/ $\mathrm{KB} 1 / 84 / 10)$. All subjects gave informed consent to participate in the study. The study group (PA) was made up of 124 people with a newly diagnosed autoimmune disease of the haematopoietic system
- pernicious anaemia. There were 85 women and 39 men aged: $\geq 60$ $(61.3 \%), 50-59(20.2 \%), 40-49(12.1 \%)$, and $30-39(6.5 \%)$ years old. The male/female sex ratio was 0.46 . Criteria for inclusion: over 18 years of age; diagnosed PA based on at least two of three diagnostic criteria: — reduced serum $B_{12}$ level (below $200 \mathrm{pg} / \mathrm{mL}$ );

- positive result for one of the following antibodies: IFAb and/or APCA;

- positive a therapeutic test, i.e. precisely defined by laboratory parameters, response to a single parenteral administration of $1000 \mu \mathrm{g}$ of vitamin $B_{12}$ in the form of an increase in the number of reticulocytes after 5-10 days (reticulocytic break), reduction of iron or LDH in the blood by $50 \%$ of baseline, regression of thrombocytopaenia or/and neutropoenia within two weeks, regression of anaemia and hyper-segmentation of granulocyte nuclei after 2-4 weeks.

Exclusion criteria: under 18 years of age; cancer; chronic renal failure $\left(\mathrm{eGFR}<30 \mathrm{ml} / \mathrm{min} / 1.73 \mathrm{~m}^{2}\right)$; chronic hepatic failure (bilirubin above $2 \mathrm{mg} \%$ ); symptomatic circulatory insufficiency; symptomatic respiratory failure; severe neurological diseases and mental disorders. The control group (C) comprised 41 people: 30 women and 11 men, of comparable age to the study group. Criteria for inclusion: over 18 years of age; exclusion of autoimmune disease based on the interview and available test results; negative antibody result of IFAb and APCA; no clinical signs of organ dysfunction; exclusion of chronic pharmacotherapy; negative history of autoimmune diseases in the family. In both groups (PA, C) blood for testing up to $20 \mathrm{ml}$ was collected in the morning, after an overnight fast, from the ulnar vein, using a vacuum system. Serum/plasma was stored at $-75^{\circ} \mathrm{C}$ until antibody determination.

\section{Methods}

IFAb (IgG) and APCA (IgG) were determined by enzyme-linked immunosorbent assay (ELISA) using a test kit from by EUROIMMUN Medizinische Labordiagnostika AG (Germany). IFAb was quantified. The interpretation of test results accepted in the experiment was as follows: $<20 \mathrm{RU} / \mathrm{mL}-$ negative result; $\geq 20 \mathrm{RU} / \mathrm{mL}$ - positive result. APCA rated semi-quantitatively. The interpretation of test results accepted in the experiment was as follows: negative result; positive result.

TPOAb (IgG) was determined by ELISA and quantified. The interpretation of the test results accepted in the experiment were as follows: < $100 \mathrm{IU} / \mathrm{mL}$ - negative result; $\geq 100 \mathrm{IU} / \mathrm{mL}$ - positive result. The assays were performed using an ELISA test kit from IBL International $\mathrm{GmBH}$, Germany. The upper limit of the standard (cut-off) recommended by the manufacturer of the set is $100 \mathrm{IU} / \mathrm{mL}$. IBL recommends the following interpretation of the test results: $<85 \mathrm{IU} / \mathrm{mL}$ - negative result, $85-125 \mathrm{IU} / \mathrm{mL}$ - uncertain result, $>125 \mathrm{IU} / \mathrm{mL}$ - positive result. IBL assessed the level of TPOAb in 160 healthy blood donors (appropriately divided by age and sex) and showed TPOAb values as follows: mean $-55 \mathrm{IU} / \mathrm{mL}$, mean $+2 \mathrm{SD}-220 \mathrm{IU} / \mathrm{mL}$, median $35 \mathrm{IU} / \mathrm{mL}, 95 \%$ (percentile) of results $\leq 110 \mathrm{IU} / \mathrm{mL}$ (reference group). The linearity of the ELISA used was within the measurement range of $15-2100 \mathrm{IU} / \mathrm{mL}$. The lower limit of detection (analytical sensitivity) of the test used was $10 \mathrm{IU} / \mathrm{mL}$. This limit was defined as three times the standard deviation of the blind test and was the lowest value of the TPOAb measured. The test kit is specific for human IgG antibodies against TPO (analytical specificity). Evaluated in order to control repeatability, the coefficient of variation $(\mathrm{CV})$ measurements within the same assay (intraassay-variation) and the variation coefficient measurements carried out at intervals of time (inter-assay-variation) in different ranges of the calibration curve were $3.7-4,1 \%$, and $4.1-7 \%$, respectively. $\mathrm{TgAb}(\mathrm{IgG})$ was determined by ELISA and quantified. The interpretation of the test results accepted in the experiment was as follows: < $100 \mathrm{IU} / \mathrm{mL}$ - negative result; $\geq 100 \mathrm{IU} / \mathrm{mL}$ - positive result. The assays were performed using an ELISA test kit from IBL International $\mathrm{GmBH}$, Germany. The cut-off recommended by the manufacturer of the set is $100 \mathrm{IU} / \mathrm{mL}$. IBL recommends the following interpretation of the test results: $<85 \mathrm{IU} / \mathrm{mL}$ - negative 
result, $85-125 \mathrm{IU} / \mathrm{mL}$ - uncertain result, > $125 \mathrm{IU} / \mathrm{mL}$ - positive result. IBL assessed the level of $\mathrm{TgAb}$ in 160 healthy blood donors (appropriately divided by age and sex) and showed TgAb values: mean $-35 \mathrm{IU} / \mathrm{mL}$, mean $+2 \mathrm{SD}-110 \mathrm{IU} / \mathrm{mL}$, median $25 \mathrm{IU} / \mathrm{mL}$ $95 \%$ (percentile) of results (reference group). The linearity of the ELISA used was within the measurement range of $15-2300 \mathrm{IU} / \mathrm{mL}$. The lower detection limit of the assay used was $10 \mathrm{IU} / \mathrm{mL}$. This limit was defined as three times the SD of the blind test and was the lowest value of the determined $\mathrm{TgAb}$ titre. The test kit is specific for human IgG antibodies against $\mathrm{Tg}$. Intra-assay-variation and inter-assay-variation in different ranges of the standard curve are $2.7-6.9 \%$ and $2.7-7.4 \%$, respectively.

AdrenalAb was determined by indirect immunofluorescence assay (IIFT) and rated qualitatively. The interpretation of test results accepted in the experiment was as follows: negative result; positive result. The assays were performed using the EUROIMMUN Medizinische Labordiagnostika AG test kit, Germany, which is intended for the in vitro testing of human antibodies against the adrenal cortex in serum or plasma. Frozen primate adrenal gland sections are incubated with diluted patient samples. In positive cases, specific antibodies of the IgA, IgG, and IgM class bind to the adrenal antigens. During the second incubation step, bound antibodies are detected by fluorescein-labelled anti-human antibodies, and this reaction is evaluated under a fluorescence microscope. The image of fluorescence (positive reaction) arises because Adrenal $\mathrm{Ab}$ reacts with frozen primate adrenal glands, and in the cortical region, the cytoplasm of steroid-producing cells exhibits granular or uniform fluorescence.

PituitaryAb was determined by indirect immunofluorescence assay (IIFT) and assessed qualitatively. The interpretation of test results accepted in the experiment was as follows: negative result; positive result. The assays were performed using the EUROIMMUN Medizinische Labordiagnostika AG test kit, which is intended for the in vitro testing of human anti-pituitary (frontal lobe) antibodies in serum or plasma. Frozen primate pituitary gland sections are incubated with diluted patient samples. In positive cases, specific antibodies of the IgA, IgG, and IgM class bind to pituitary antigens. During the second incubation step, bound antibodies are detected by fluorescein-labelled anti-human antibodies, and this reaction is evaluated under a fluorescence microscope. Fluorescence (positive reaction) is produced because pituitary antibodies react with different pituitary structures, and in cells producing hormones of the anterior pituitary gland, granular cytoplasmic fluorescence is visible (the target antigen for these antibodies may be prolactinproducing cells)

The test kits used for the AdrenalAb and PituitaryAb assays do not show cross-reactivity and interference with haemolytic, lipaemic, and hyperbilirubinaemia sera. The results for all samples of 10 different series evaluated for repeatability control differed by no more than \pm 1 degree of fluorescence intensity (thus the reproducibility of the test was confirmed). The intensity of specific fluorescence in the form of a numerical value is called the fluorescence intensity level. These values range from " 0 " (no specific fluorescence) to " 5 " (extremely strong fluorescence). Inter-serial repeatability also did not differ by more than \pm 1 degree of fluorescence intensity. With the same result, the reproducibility of the test was confirmed. The sensitivity and specificity of the IIFT test used is $100 \%$, and these values were determined from the tests of samples previously classified by the reference centres.

Vitamin $\mathrm{B}_{12}$, iron, ferritin, folic acid; peripheral blood count with smear and platelets by manual method, INR, APTT, PT, fibrinogen D-dimers; proteinogram, total protein; basic biochemical tests (creatinine, glucose, bilirubin, Alat, electrolytes, lipidogram, uric acid, $\mathrm{CRP}$ ); and TSH, fT4, and fT3 were determined with routine kits using biochemical analysers in the course of haematological diagnostics.

\section{Statistical methods and tools}

In the statistical elaboration, variables were available in qualitative (nominal) form (IFAb, APCA, TPOAb, TgAb, PituitaryAb,
Adrenal $\mathrm{Ab}$ ) and three parameters on the quantitative scale (IFAb, TPOAb, TgAb). Relations for which $p<0.05$ were considered as important. To assess the relationship between the nominal values of antibodies, the Pearson's Chi-squared independence test was used. A hierarchy of risk of antibody development in the study group was developed. Risk models for the emergence of antithyroid antibodies in the study group were performed. For these variables, logarithmic-normal distributions were used that describe the distribution of these antibodies. The study used a multidimensional MCA correspondence model for the occurrence of certain groups of antibodies in the study group. Thanks to this analysis, groups of clusters of certain measured parameters, i.e. age, sex, antibodies, and diseases caused by them, could be selected. In the last part of the analysis for quantitative variables, Pearson's correlations were calculated.

\section{Results}

The presence of at least one of the two antithyroid antibodies involved in the pathogenesis of AITD affects more than $40 \%$ of patients with PA. TPOAb is found in patients with PA more often than $\mathrm{TgAb}$, and simultaneous occurrence of TPOAb and TgAb in the blood of these patients occurs in every fifth patient. AdrenalAb and PituitaryAb in PA patients occur sporadically. In those considered healthy (control group), approximately $12 \%$ had at least one of two analysed antithyroid antibodies, and the percentage of both antibodies was $2.4 \%$. TgAb was twice as likely to be present in this group than TPOAb. AdrenalAb and PituitaryAb are not found in healthy persons (Tab. I, II). Analysis of the coexistence of these antibodies showed that patients with PA lack the basis for recognising APS variants with respect to the analysed antibodies (Tab. III) as summarised in the probabilistic assessment of the odds [0-100\%] and the risk of appearance of antibodies to endocrine glands in patients with PA. The risk of the presence of antibodies against endocrine glands in patients with PA can be classified in the following order: TPOAb and/or TgAb $-41.1 \%$, TPOAb $-36.3 \%$, TgAb $-25.0 \%$, TPOAb and TgAb $-20.2 \%$, AdrenalAb - $1.6 \%$, PituitaryAb - 0.8\% (Tab. IV). For the most common antibodies, a model of risk/chance of their occurrence in patients with PA was performed. These data (Fig. 1,2) are consistent with the calculations presented earlier (Tab. I, IV). In order to verify the thesis whether in patients with PA there is correlation in the simultaneous occurrence of antibodies involved in the development of autoimmune endocrine diseases (AITD, APS) with antibodies involved in the pathogenesis of PA, the $\chi^{2}$ independence test was used. TPOAb and/or $\mathrm{TgAb}$ (mainly TPOAb) are more frequently present in patients with PA, who have IFAb and/or APCA. This correlation is most evident in patients with concurrent IFAb and APCA (Tab. V). This analysis was extended by multidimensional analysis of MCA correspondence of the occurrence of antibody groups in patients with 
Table I. Prevalence of antibodies involved in the development of autoimmune thyroid disease (AITD) i.e. anti-thyroid peroxidase $(T P O A b)$ and anti-thyroglobulin (TgAb) antibodies in pernicious anaemia patients (PA) and in control (C) groups

\begin{tabular}{|c|c|c|c|c|c|c|}
\hline \multirow[b]{2}{*}{ Antibodies } & \multirow[b]{2}{*}{ Response } & \multicolumn{2}{|c|}{ Group } & \multicolumn{3}{|c|}{$\chi^{2}$ test } \\
\hline & & $\begin{array}{c}\text { Pernicious anaemia (PA) } \\
\%(\mathrm{n})\end{array}$ & $\begin{array}{l}\text { Control (C) } \\
\% \text { (n) }\end{array}$ & $\chi^{2}$ & df & p \\
\hline \multirow{2}{*}{ TPOAb } & Negative result & $63.70 \%(79)$ & $95.10 \%(39)$ & \multirow{2}{*}{14.925} & \multirow{2}{*}{1} & \multirow{2}{*}{0.000} \\
\hline & Positive result & $36.30 \%(45)$ & $4.90 \%(2)$ & & & \\
\hline \multirow{2}{*}{$\operatorname{Tg} A b$} & Negative result & $75.00 \%(93)$ & $90.20 \%(37)$ & \multirow{2}{*}{4.284} & \multirow{2}{*}{1} & \multirow{2}{*}{0.038} \\
\hline & Positive result & $25.00 \%(31)$ & $9.80 \%(4)$ & & & \\
\hline \multirow{2}{*}{ TPOAb and/or TgAb } & Negative result & $58.90 \%(73)$ & $87.80 \%(36)$ & \multirow{2}{*}{11.505} & \multirow{2}{*}{1} & \multirow{2}{*}{0.001} \\
\hline & Positive result & $41.10 \%(51)$ & $12.20 \%(5)$ & & & \\
\hline \multirow{2}{*}{ TPOAb and $\mathrm{TgAb}$} & Negative result & $79.80 \%(99)$ & $97.60 \%(40)$ & \multirow{2}{*}{7.29} & \multirow{2}{*}{1} & \multirow{2}{*}{0.007} \\
\hline & Positive result & $20.20 \%(25)$ & $2.40 \%(1)$ & & & \\
\hline
\end{tabular}

$\mathrm{n}$ - number of patients/controls

Table II. Prevalence of anti-adrenal gland (AdrenalAb) and anti-pituitary gland (PituitaryAb) antibodies in pernicious anaemia patients (PA) and in control (C) groups

\begin{tabular}{lcccccc}
\hline \multirow{2}{*}{ Antibodies } & Response & \multicolumn{2}{c}{ Group } & \multicolumn{2}{c}{$\chi^{2}$ test } \\
\cline { 3 - 7 } & & $\begin{array}{c}\text { Pernicious anaemia (PA) } \\
\%(\mathbf{n})\end{array}$ & $\begin{array}{c}\text { Control (C) } \\
\%(\mathbf{n})\end{array}$ & $\chi^{2}$ & $\mathbf{d f}$ & $\mathbf{p}$ \\
\hline AdrenalAb & Positive result & $1.60 \%(2)$ & $0 \%(0)$ & 0.669 & 1 & 0.413 \\
\hline PituitaryAb & Positive result & $0.80 \%(1)$ & $0 \%(0)$ & 0.333 & 1 & 0.564 \\
\hline
\end{tabular}

$\mathrm{n}$ - number of patients/controls

Table III. Coexistence of antibodies involved in the development of possible variants of autoimmune polyendocrine syndrome (APS) in pernicious anaemia patients (PA) and in control (C) groups

\begin{tabular}{|c|c|c|c|c|c|c|}
\hline \multirow[b]{2}{*}{ Coexistence of antibodies } & \multirow[b]{2}{*}{ Response } & \multicolumn{2}{|c|}{ Group } & \multicolumn{3}{|c|}{$\chi^{2}$ test } \\
\hline & & $\begin{array}{c}\text { Pernicious anaemia (PA) } \\
\%(\mathrm{n})\end{array}$ & $\begin{array}{c}\text { Control (C) } \\
\% \text { (n) }\end{array}$ & $\chi^{2}$ & df & p \\
\hline TPOAb and $\operatorname{Tg} A b+$ Adrenal $A b$ & Positive result & $0.80 \%(1)$ & $0 \%(0)$ & 0.333 & 1 & 0.564 \\
\hline TPOAb or TgAb + PituitaryAb & Positive result & $0 \%(0)$ & $0 \%(0)$ & & & \\
\hline AdrenalAb + PituitaryAb & Positive result & $0 \%(0)$ & $0 \%(0)$ & & & \\
\hline
\end{tabular}

$\mathrm{n}$ - number of patients/controls

PA, which allowed us to create a statistically significant $\left(\chi^{2}=4584.51 ; \mathrm{p}<0.01\right)$ model (distribution of factors and their clusters on the Burt matrix) based on which it has been shown that the simultaneous presence of antibodies "IFAb and/or APCA" with antibodies "TPOAb and/or $\mathrm{TgAb}$ " is most likely in women over 45 years of age (data not included in the table/figure).

For the quantified antibodies [IU/mL], descriptive statistics were calculated. TPOAb in the PA group: mean 199.5 \pm SD 326.94; min. 1.53; max. 1548.4; median 26.85. TPOAb in group C: mean $30.6 \pm$ SD 74.71; min. 0 ; max. 460,51; median 11.82. TgAb in the PA group: mean 442.11 \pm SD 1281.37; min. 3.3; max. 6781.34; median 34.72. TgAb in group $\mathrm{C}$ : mean $60.63 \pm \mathrm{SD}$ 131.12; min. 4.7; max. 607.92; median 15.89 (data not included in the table). In the last stage of the analysis, Pearson's correlations were calculated for quantitative determinations in the blood. In the PA group, if the concentration of IFAb in the blood increases, then the concentration of $\mathrm{TgAb}$ will increase slightly. In addition, a moderately increased amount of TPOAb is accompanied by an increase in the amount of $\mathrm{TgAb}$ (Tab. VI). In group C, a moderately strong increase in TPOAb was accompanied by an increase in the amount of $\mathrm{TgAb}(\mathrm{R}=0.639, \mathrm{p}<0.01)$ (data not included in the table). 
Table IV. Risk of the presence of endocrine gland antibodies in pernicious anaemia patients

\begin{tabular}{ll}
\hline $\begin{array}{l}\text { Risk of the presence of endocrine gland antibodies } \\
\text { in pernicious anaemia patients }\end{array}$ \\
\hline TPOAb and/or TgAb & $41.1 \%$ \\
\hline TPOAb & $36.3 \%$ \\
\hline TgAb & $25.0 \%$ \\
\hline TPOAb and TgAb & $20.2 \%$ \\
\hline AdrenalAb & $1.6 \%$ \\
\hline PituitaryAb & $0.8 \%$ \\
\hline TPOAb and/or TgAb + AdrenalAb & $0.8 \%$ \\
\hline TPOAb + AdrenalAb & $0.8 \%$ \\
\hline TgAb + AdrenalAb & $0.8 \%$ \\
\hline TPOAb and TgAb + AdrenalAb & $0.8 \%$ \\
\hline TPOAb or TgAb + PituitaryAb & $\sim 0.0 \%$ \\
\hline AdrenalAb + PituitaryAb & $\sim 0.0 \%$ \\
\hline
\end{tabular}

TPOAb - anti-thyroid peroxidase antibody; $\operatorname{Tg} A b$ - anti-thyroglobulin antibody; Adrenal $\mathrm{Ab}$ — anti-adrenal gland antibody; Pituitary $\mathrm{Ab}$ — anti-pituitary gland antibody

\section{Discussion}

Among 126 Chinese PA patients, $44 \%$ had TPOAb/TgAb and $13.5 \%$ AITD. TPOAb/TgAb occurred in 33\% (16 of 49 ) of male and $52 \%$ (40 of 77 ) of female patients. The $\mathrm{TPOAb} / \mathrm{TgAb}$ did not affect the clinical course of PA but was associated with an enhanced risk of developing AITD and vitiligo. Overall, AITD (before and after the appearance of PA) occurred in 23\% (13 of 56) and $5.7 \%$ (4 of 70) of the patients with and without APCA (IFAb, was not determined) [34]. In turn, in a recently

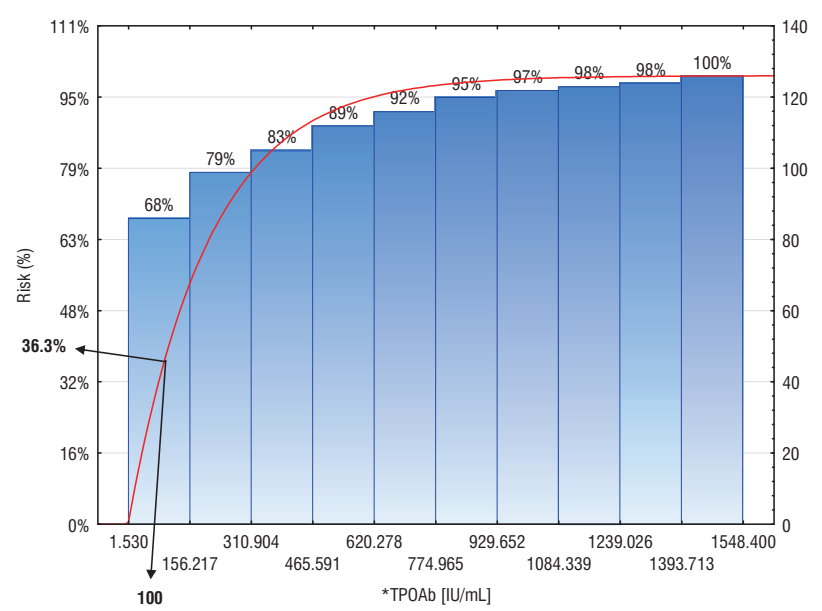

Figure 1. The risk/chance of TPOAb positive result $\geq 100 \mathrm{IU} / \mathrm{mL}$ in patients with pernicious anaemia (PA). The risk function for TPOAb of the occurrence of $x$ value on the above-mentioned scale variable is expressed by the formula ${ }^{*}$ TPOAb [IU/mL] $=126^{*}$ iLognorm $(x ; 3.7854 ; 1.9426)$ published retrospective observation of 188 patients with PA, non-haematological diseases with autoimmune aetiology were sought. Diagnosis of AITD was based on clinical examination and the presence of TPOAb and/or TgAb. Diagnosis of Addison's disease was based on clinical data, hormonal status, and the presence of anti-adrenal antibodies. In a newly formed group of 74 (male 13, female 61, male/female sex ratio 0.2; age range 25-98 years) patients with PA and at least one other autoimmune disease the following was shown: Hashimoto's disease in 45 people $(60.8 \%$ in 36 women and nine men), Addison's in five (6.8\%) and Graves' in 12 people (16.6\%) [25]. In our study, in the group of 124 people with PA, TPOAb and/or TgAb occur in $41.1 \%$ and AdrenalAb in $1.6 \%$. The results from the two above-mentioned articles seem to be consistent with those obtained by us. In our work, the risk of having antithyroid antibodies in patients with PA is additionally attributed to their specific types. We also show that TPOAb and/or TgAb (mainly TPOAb) are more frequently present in patients with PA who have IFAb and/or APCA, and this relationship is most evident in patients with associated occurrence both of IFAb and APCA. We also point out that in patients with PA, the simultaneous presence of antibodies IFAb and/or APCA with TPOAb and/or TgAb antibodies is most likely in women over 45 years of age. In view of the fact that PA usually affects adults over 60 years of age, but about $50 \%$ of patients are $<60$ years old [11], we assessed the levels of antithyroid antibodies in relation to age. So far, the association between AITD and PA among people aged 65 years or older has been confirmed, as well as a progressive increase in the incidence of these diseases

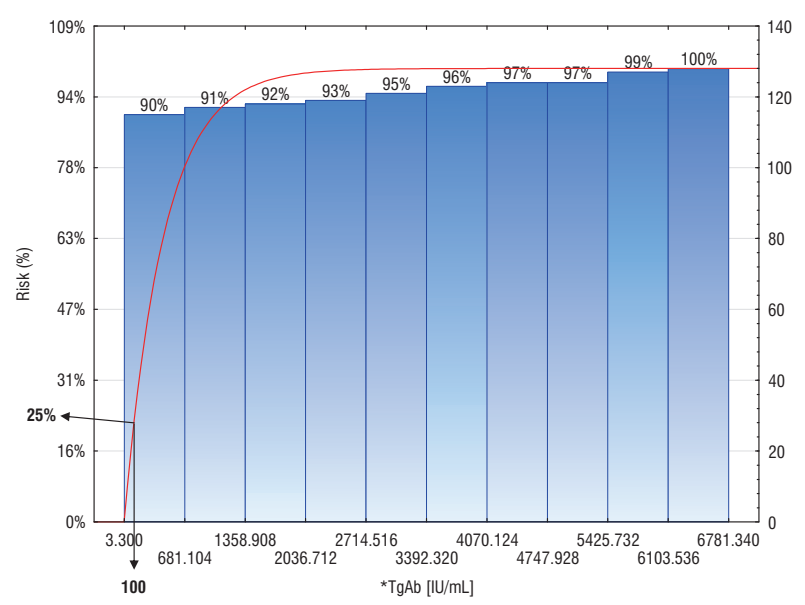

Figure 2. The risk/chance of a positive $T g A b$ result $\geq 100 \mathrm{IU} / \mathrm{mL}$ in patients with pernicious anaemia (PA). The risk function for TgAb of the occurrence of $x$ value on the above-mentioned scale variable is expressed by the formula ${ }^{*} \mathrm{TgAb}$ [IU/mL] $=128 *$ iLognorm $(x ; 4.0654 ; 1.7032)$ 
Table V. Coexistence of antibodies involved in the development of autoimmune endocrine disease (AITD, APS) with antibodies involved in the pathogenesis of pernicious anaemia in the pernicious anaemia patient group (PA)

\begin{tabular}{|c|c|c|c|c|c|c|c|c|c|}
\hline \multirow{3}{*}{ Antibodies } & \multirow{3}{*}{ Result } & \multicolumn{2}{|c|}{ IFAb } & \multicolumn{2}{|c|}{ APCA } & \multicolumn{2}{|c|}{ IFAb and/or APCA } & \multicolumn{2}{|c|}{ IFAb and APCA } \\
\hline & & Negative & Positive & Negative & Positive & Negative & Positive & Negative & Positive \\
\hline & & $\%(\mathbf{n})$ & $\%(\mathbf{n})$ & $\%(\mathbf{n})$ & $\%(\mathbf{n})$ & $\%(\mathbf{n})$ & $\%(\mathbf{n})$ & $\%(\mathbf{n})$ & $\%(\mathbf{n})$ \\
\hline \multirow{2}{*}{ TPOAb } & Negative & $\begin{array}{c}72.10 \% \\
(62)\end{array}$ & $\begin{array}{c}44.70 \% \\
(17)\end{array}$ & $\begin{array}{c}74.60 \% \\
(50)\end{array}$ & $\begin{array}{c}50.90 \% \\
(29)\end{array}$ & $\begin{array}{c}79.20 \% \\
(38)\end{array}$ & $\begin{array}{c}53.90 \% \\
(41)\end{array}$ & $\begin{array}{c}70.50 \% \\
(74)\end{array}$ & $\begin{array}{c}26.30 \% \\
\text { (5) }\end{array}$ \\
\hline & Positive & $\begin{array}{c}27.90 \% \\
(24)\end{array}$ & $\begin{array}{c}55.30 \% \\
(21)\end{array}$ & $\begin{array}{c}25.40 \% \\
(17)\end{array}$ & $\begin{array}{c}49.10 \% \\
(28)\end{array}$ & $\begin{array}{c}20.80 \% \\
(10)\end{array}$ & $\begin{array}{c}46.10 \% \\
(35)\end{array}$ & $\begin{array}{c}29.50 \% \\
(31)\end{array}$ & $\begin{array}{c}73.70 \% \\
(14)\end{array}$ \\
\hline \multirow{2}{*}{$\begin{array}{l}\text { TPOAb } \\
\text { and/or TgAb }\end{array}$} & Negative & $\begin{array}{c}65.10 \% \\
(56)\end{array}$ & $\begin{array}{c}44.70 \% \\
(17)\end{array}$ & $\begin{array}{c}67.20 \% \\
(45)\end{array}$ & $\begin{array}{c}49.10 \% \\
(28)\end{array}$ & $\begin{array}{c}68.80 \% \\
(33)\end{array}$ & $\begin{array}{c}52.60 \% \\
(40)\end{array}$ & $\begin{array}{c}64.80 \% \\
(68)\end{array}$ & $\begin{array}{c}26.30 \% \\
(5)\end{array}$ \\
\hline & Positive & $\begin{array}{c}34.90 \% \\
(30)\end{array}$ & $\begin{array}{c}55.30 \% \\
(21)\end{array}$ & $\begin{array}{c}32.80 \% \\
(22)\end{array}$ & $\begin{array}{c}50.90 \% \\
(29)\end{array}$ & $\begin{array}{c}31.30 \% \\
(15)\end{array}$ & $\begin{array}{c}47.40 \% \\
(36)\end{array}$ & $\begin{array}{c}35.20 \% \\
(37)\end{array}$ & $\begin{array}{c}73.70 \% \\
(14)\end{array}$ \\
\hline
\end{tabular}

\begin{tabular}{|c|c|c|c|c|c|}
\hline Antibodies & & IFAb & APCA & IFAb and/or APCA & IFAb and APCA \\
\hline & $\chi^{2}$ & 8531 & 7.514 & 8.093 & 13.57 \\
\hline \multirow[t]{3}{*}{ TPOAb } & df & 1 & 1 & 1 & 1 \\
\hline & $\mathrm{p}$ & 0.003 & 0.006 & 0.004 & 0 \\
\hline & $\chi^{2}$ & 4.521 & 4.14 & & 9.821 \\
\hline \multirow[t]{2}{*}{ TPOAb and/or TgAb } & df & 1 & 1 & NS & 1 \\
\hline & $\mathrm{p}$ & 0.033 & 0.042 & & 0.002 \\
\hline $\operatorname{TgAb}$ & $\mathrm{p}$ & NS & NS & NS & NS \\
\hline AdrenalAb & $\mathrm{p}$ & NS & NS & NS & NS \\
\hline PituitaryAb & $\mathrm{p}$ & NS & NS & NS & NS \\
\hline TPOAb and TgAb & $\mathrm{p}$ & NS & NS & NS & NS \\
\hline TPOAb and/or TgAb + AdrenalAb & $\mathrm{p}$ & NS & NS & NS & NS \\
\hline TPOAb + AdrenalAb & $\mathrm{p}$ & NS & NS & NS & NS \\
\hline $\operatorname{Tg} A b+$ Adrenal $A b$ & $\mathrm{p}$ & NS & NS & NS & NS \\
\hline TPOAb and TgAb + AdrenalAb & $\mathrm{p}$ & NS & NS & NS & NS \\
\hline TPOAb and/or TgAb + PituitaryAb & . & . & . & . & . \\
\hline TPOAb + PituitaryAb & . & . & . & . & . \\
\hline $\operatorname{TgAb}+$ PituitaryAb & . & . & . & . & . \\
\hline TPOAb and $\operatorname{Tg} A b+$ PituitaryAb & . & . & . & . & . \\
\hline AdrenalAb and PituitaryAb & . & . & . & . & . \\
\hline
\end{tabular}

TPOAb — anti-thyroid peroxidase antibody; TgAb — anti-thyroglobulin antibody; AdrenalAb — anti-adrenal gland antibody; PituitaryAb — anti-pituitary gland antibody; IFAb - anti-intrinsic factor antibody; APCA — anti-parietal cell antibody; NS — no significance; $n$ - number of patients

Table VI. Pearson correlations for the group with pernicious anaemia $(P A)$

\begin{tabular}{lccccc}
\hline PA group & & Age & IFAb & TPOAb & TgAb \\
\hline \multirow{2}{*}{ Age } & $\mathrm{R}$ & 1 & 0.054 & -0.091 & -0.065 \\
\cline { 2 - 6 } & $\mathrm{p}$ & & 0.550 & 0.316 & 0.473 \\
\hline $\mathrm{IFAb}$ & $\mathrm{R}$ & 0.054 & 1 & 0.136 & $\mathbf{0 . 2 0 3}$ \\
\cline { 2 - 6 }$[\mathrm{RU} / \mathrm{mL}]$ & $\mathrm{p}$ & 0.550 & & 0.133 & 0.024 \\
\hline $\mathrm{TPOAb}$ & $\mathrm{R}$ & -0.091 & 0.136 & 1 & $\mathbf{0 . 4 9 0}$ \\
\hline$[\mathrm{IU} / \mathrm{mL}]$ & $\mathrm{p}$ & 0.316 & 0.133 & & 0.01 \\
\hline $\mathrm{TgAb}$ & $\mathrm{R}$ & -0.065 & $\mathbf{0 . 2 0 3}$ & $\mathbf{0 . 4 9 0}$ & 1 \\
\hline$[\mathrm{IU} / \mathrm{mL}]$ & $\mathrm{p}$ & 0.473 & 0.024 & $<0.01$ & \\
\hline
\end{tabular}

$\mathrm{R}$ - correlation coefficient
[35]. In almost half of the PA patients we examined, we found a clear increase in the amount of at least one of the two antibodies responsible for the development of AITD, which is sufficient to recognise the increased risk of Hashimoto's disease, and in combination with hormonal and ultrasound assessment determines the diagnosis of this most common thyroid disease. We found both TPOAb and TgAb in every fifth patient with $\mathrm{PA}$, which suggests an even deeper autoimmune alert. In our study, in patients with PA, TPOAb is more frequent than $\operatorname{TgAb}$. There is a widespread opinion that among these two antibodies for the diagnosis of AITD, TPOAb is more specific. Considering this, screening for AITD should start with the TPOAb determination. We also 
describe the incidence of AdrenalAb in patients with PA. We were the first to investigate the incidence of PituitaryAb, not only in patients with PA but also in patients with autoimmune haematological disease in general.

Although the results of previously published research related to the clinical issue described here are varied, they sometimes depend on the studied population, but still prove the existence of an autoimmune alert in patients with PA. For example, in the Korean population, Hashimoto's thyroiditis was found in $6.1 \%$ (6 out of 97) of PA patients, vitiligo in 3\%, and Graves' disease in $4.1 \%$. Type 1 diabetes mellitus, Addison's disease, and ankylosing spondylitis were found in one patient each. Two per cent of patients already had stomach cancer at the time of diagnosis of PA. In total, AITD was present in $10.2 \%$ of this study population, which is much lower than the $24 \%$ to $27 \%$ in Western populations [6]. At present, it is difficult to explain such a distinct difference. Another newly published work shows, that $40 \%$ of patients with autoimmune gastritis also present Hashimoto's thyroiditis [23]. The issue discussed here was also analysed in the opposite way - the incidence of PA in patients with non-haematopoietic autoimmune disease was examined. PA is sometimes preceded by AITD [21] by several years. A prevalence of IFAb at $3.5 \%$, being higher in patients with AITD than in those with non-autoimmune thyroid dysfunction, was found [36]. In $12 \%$ of patients with Addison's disease, IFAb is found [37]. 23.5\% patients with AITD were diagnosed with APCA [38]. APCA positivity was significantly more prevalent in Hashimoto than in non-Hashimoto thyroiditis patients (12.9 vs. $1.6 \%, \mathrm{p}=0.017$ ) [39]. PA was found in $18.6 \%$ of the patients with AITD, and the $45 \%$ of PA presented with AITD, mainly in women $(R R=6.0)$. The average time in diagnosing the second disease was about eight years. When there was a third autoimmune disease the likelihood of AITD and PA increased fourfold. Patients with AITD and taking drugs that affected the absorption of vitamin $B_{12}$ had double the probability of developing a PA compared with those who were not taking medications [35]. The occurrence of anti-thyroid antibodies in patients with PA has also been described much earlier at the level of 33\% [17], which is consistent with the clinical observation of the coexistence of diseases with autoimmune aetiology in clinical medicine $[13,16,18-20]$. Susceptibility to PA appears to be genetically determined, although the mode of inheritance remains unknown. Similarly, there is evidence for the role of genetic factors binding PA with other autoimmune diseases [4, 19-22]. The phenomenon of the coexistence of autoimmune diseases of the endocrine glands with gastroenterological and rheumatic diseases is referred to as autoimmune polyendocrine syndrome (APS). APS has a number of types and subtypes. The coexistence of PA and AITD forms APS type IIIb alongside such autoimmune diseases as diabetes, alopecia, vitiligo, and chronic atrophic gastritis. In APS IIIb, Hashimoto thyroiditis represents the pivotal disorder. Progress has been made in the diagnosis of autoimmune diseases in recent years, also in terms of sensitivity and specificity of antibody determinations, which was an additional justification for conducting this analysis.

\section{Conclusions}

In patients with pernicious anaemia it is justified to carry out screening evaluation towards autoimmune thyroid diseases, which in the first place should be based on a determination of the concentration of TPOAb (next $\mathrm{TgAb}$ ) in the blood. The assessment of antithyroid antibodies should be recommended primarily to patients with pernicious anaemia, who have IFAb and/or APCA and in particular those with concurrent IFAb and APCA.

\section{Acknowledgment}

Funding: This work was supported by the Medical University of Silesia grant nos. KNW-1-135/N/3/0, KNW-1-056/N/4/0, KNW-1-158/K/5/0. Competing interests: The authors have declared that no competing interests exist.

\section{References}

1. Quincke H, Gunn J. Abstract of a Lecture on Pernicious Anæmia. Edinb Med J. 1877; 22(12): 1087-1098, indexed in Pubmed: 29640342.

2. Schwartz M, Schwartz M, Schwartz M, et al. Antibody to intrinsic factor. Scand J Clin Lab Invest Suppl. 1967; 95: 19-27, indexed in Pubmed: 6062164.

3. Toh BH, Alderuccio F. Pernicious Anaemia. Autoimmunity. 2009; 37(4): 357-361, doi: 10.1080/08916930410001705439.

4. Andres E, Serraj K. Optimal management of pernicious anemia. J Blood Med. 2012; 3: 97-103, doi: 10.2147/JBM.S25620, indexed in Pubmed: 23028239

5. Park JY, Lam-Himlin D, Vemulapalli R. Review of autoimmune metaplastic atrophic gastritis. Gastrointest Endosc. 2013; 77(2): 284-292, doi: 10.1016/j.gie.2012.09.033, indexed in Pubmed: 23199649.

6. Song IC, Lee HJ, Kim HJ, et al. A multicenter retrospective analysis of the clinical features of pernicious anemia in a Korean population. J Korean Med Sci. 2013; 28(2): 200-204, doi: 10.3346/jkms.2013.28.2.200, indexed in Pubmed: 23400269.

7. Stabler SP. Clinical practice. Vitamin B12 deficiency. N Engl J Med. 2013; 368(2): 149-160, doi: 10.1056/NEJMcp1113996, indexed in Pubmed: 23301732.

8. Bizzaro N, Antico A. Diagnosis and classification of pernicious anemia. Autoimmun Rev. 2014; 13(4-5): 565-568, doi: 10.1016/j.autrev.2014.01.042, indexed in Pubmed: 24424200.

9. Toh BH. Diagnosis and classification of autoimmune gastritis. Autoimmun Rev. . 2014; 13(4-5): 459-462, doi: 10.1016/j.autrev.2014.01.048, indexed in Pubmed: 24424193.

10. Murphy G, Dawsey SM, Engels EA, et al. Cancer Risk After Pernicious Anemia in the US Elderly Population. Clin Gastroenterol Hepatol. 2015; 13(13): 2282-9.e1, doi: 10.1016/j.cgh.2015.05.040, indexed in Pubmed: 26079040.

11. Rojas Hernandez CM, Oo TH. Advances in mechanisms, diagnosis, and treatment of pernicious anemia. Discov Med. 2015; 19(104): 159-168, indexed in Pubmed: 25828519.

12. Watanabe $\mathrm{S}$, Ide N, Ogawara $\mathrm{H}$, et al. High percentage of regulatory $\mathrm{T}$ cells before and after vitamin B12 treatment in patients with pernicious anemia. Acta Haematol. 2015; 133(1): 83-88, doi: 10.1159/000362356, indexed in Pubmed: 25170761. 
13. Rusak E, Chobot A, Krzywicka A, et al. Anti-parietal cell antibodies - diagnostic significance. Adv Med Sci. 2016; 61(2): 175-179, doi: 10.1016/j.advms.2015.12.004, indexed in Pubmed: 26918709.

14. Hughes JW, Muegge BD, Tobin GS, et al. High-risk gastric pathology and prevalent autoimmune diseases in patients with pernicious anemia. Endocr Pract. 2017; 23(11): 1297-1303, doi: 10.4158/EP-2017-0056, indexed in Pubmed: 29190137.

15. Lipiński M, Rydzewska G, Foltyn W, et al. Gastroduodenal neuroendocrine neoplasms, including gastrinoma — management guidelines (recommended by the Polish Network of Neuroendocrine Tumours). Endokrynol Pol. 2017; 68(2): 138-153, doi: 10.5603/EP.2017.0016, indexed in Pubmed: 28540972.

16. Nagao T, Hirokawa M. Diagnosis and treatment of macrocytic anemias in adults. J Gen Fam Med. 2017; 18(5): 200-204, doi: 10.1002/jgf2.31, indexed in Pubmed: 29264027.

17. Markson JL, Moore JM. Thyroid Auto-antibodies in Pernicious Anaemia. Br Med J. 1962; 2(5316): 1352-1355, indexed in Pubmed: 20789550.

18. Toh BH, van Driel IR, Gleeson PA. Pernicious anemia. N Engl J Med. 1997; 337(20): 1441-1448, doi: 10.1056/NEJM199711133372007, indexed in Pubmed: 9358143.

19. Fernando MM, Stevens CR, Walsh EC, et al. Defining the role of the MHC in autoimmunity: a review and pooled analysis. PLoS Genet. 2008; 4(4): e1000024, doi: 10.1371/journal.pgen.1000024, indexed in Pubmed: 18437207.

20. Nass FR, Kotze LM, Nisihara RM, et al. Autoantibodies in relatives of celiac disease patients: a follow-up of 6-10 years. Arq Gastroenterol. 2012; 49(3): 199-203, indexed in Pubmed: 23011242.

21. Tozzoli R, Kodermaz G, Perosa AR, et al. Autoantibodies to parietal cells as predictors of atrophic body gastritis: a five-year prospective study in patients with autoimmune thyroid diseases. Autoimmun Rev. 2010; 10(2): 80-83, doi: 10.1016/j.autrev.2010.08.006, indexed in Pubmed: 20696284.

22. Banka S, Ryan $K$, Thomson W, et al. Pernicious anemia - genetic insights. Autoimmun Rev. 2011; 10(8): 455-459, doi: 10.1016/j.autrev.2011.01.009, indexed in Pubmed: 21296191.

23. Cellini M, Santaguida MG, Virili C, et al. Hashimoto's Thyroiditis and Autoimmune Gastritis. Front Endocrinol (Lausanne). 2017; 8: 92, doi: 10.3389/fendo.2017.00092, indexed in Pubmed: 28491051.

24. Tokić S, Štefanić M, Karner I, et al. Altered expression of CTLA-4, CD28, VDR, and CD45 mRNA in T cells of patients with Hashimoto's thyroiditis - a pilot study. Endokrynol Pol. 2017; 68(3): 274-828, doi: 10.5603/EP.2017.0020, indexed in Pubmed: 28660994.

25. Zulfiqar AA, Andres E. Association pernicious anemia and autoimmune polyendocrinopathy: a retrospective study. J Med Life. 2017; 10(4): 250-253, indexed in Pubmed: 29362601.

26. Zauli D, Tosti A, Biasco G, et al. Prevalence of autoimmune atrophic gastritis in vitiligo. Digestion. 1986; 34(3): 169-172, doi: 10.1159/000199325, indexed in Pubmed: 3758513.

27. Davidson RJ, Atrah HI, Sewell HF. Longitudinal study of circulating gastric antibodies in pernicious anaemia. J Clin Pathol. 1989; 42(10): 1092-1095, indexed in Pubmed: 2584410.
28. Carmel R. Reassessment of the relative prevalences of antibodies to gastric parietal cell and to intrinsic factor in patients with pernicious anaemia: influence of patient age and race. Clin Exp Immunol. 1992; 89(1): 74-77, indexed in Pubmed: 1628426.

29. Carmel R. How I treat cobalamin (vitamin B12) deficiency. Blood. 2008; 112(6): 2214-2221, doi: 10.1182/blood-2008-03-040253, indexed in Pubmed: 18606874

30. De Bellis A, Bizzarro A, Conte M, et al. Antipituitary antibodies in adults with apparently idiopathic growth hormone deficiency and in adults with autoimmune endocrine diseases. J Clin Endocrinol Metab. 2003; 88(2): 650-654, doi: 10.1210/jc.2002-021054, indexed in Pubmed: 12574195

31. Bellastella G, Rotondi M, Pane E, et al. Italian Autoimmune Hypophysitis Network Study. Predictive role of the immunostaining pattern of immunofluorescence and the titers of antipituitary antibodies at presentation for the occurrence of autoimmune hypopituitarism in patients with autoimmune polyendocrine syndromes over a five-year follow-up. J Clin Endocrinol Metab. 2010; 95(8): 3750-3757, doi: 10.1210/jc.2010-0551, indexed in Pubmed: 20501686.

32. Guaraldi F, Caturegli P, Salvatori R. Prevalence of antipituitary antibodies in acromegaly. Pituitary. 2012; 15(4): 490-494, doi: 10.1007/s11102-011-0355-7, indexed in Pubmed: 22002711.

33. Ricciuti A, De Remigis A, Landek-Salgado MA, et al. Detection of pituitary antibodies by immunofluorescence: approach and results in patients with pituitary diseases. J Clin Endocrinol Metab. 2014; 99(5): 1758-1766, doi: 10.1210/jc.2014-1049, indexed in Pubmed: 24606106.

34. Chan JC, Liu HS, Kho BC, et al. Pattern of thyroid autoimmunity in chinese patients with pernicious anemia. Am J Med Sci. 2009; 337(6): 432-437, doi: 10.1097/MAJ.0b013e31819c0ecf, indexed in Pubmed: 19525662

35. Velarde-Mayol C, de la Hoz-García B, del Cañizo-Fernández-Roldán C, et al. [Pernicious anemia and autoimmune thyroid diseases in elderly people]. Rev Esp Geriatr Gerontol. 2015; 50(3): 126-128, doi: 10.1016/j. regg.2014.10.004, indexed in Pubmed: 25579235.

36. Morel S, Georges A, Bordenave L, et al. Thyroid and gastric autoimmune diseases. Ann Endocrinol (Paris). 2009; 70(1): 55-58, doi: 10.1016/j. ando.2008.11.003, indexed in Pubmed: 19150051.

37. Fichna M, Fichna P, Gryczyńska M. Screening for associated autoimmune disorders in Polish patients with Addison's disease. Endocrine. 2010; 37(2): 349-360, doi: 10.1007/s12020-010-9312-x, indexed in Pubmed: 20960274.

38. Castoro C, Le Moli R, Arpi ML, et al. Association of autoimmune thyroid diseases, chronic atrophic gastritis and gastric carcinoid: experience from a single institution. J Endocrinol Invest. 2016; 39(7): 779-784, doi: 10.1007/s40618-016-0445-5, indexed in Pubmed: 26928404

39. Cicone F, Papa A, Lauri C, et al. Thyro-gastric autoimmunity in patients with differentiated thyroid cancer: a prospective study. Endocrine. 2015; 49(1): 163-169, doi: 10.1007/s12020-014-0424-6, indexed in Pubmed: 25213471. 